\title{
INHIBITION OF HEPATIC ALDEHYDE DEHYDROGENASE BY CARBON TETRACHLORIDE: AN IN VITRO STUDY
}

\author{
M. F. Kenel ${ }^{*}$ and A. P. KulKarNi \\ Toxicology Program, Department of Environmental and Industrial Health, School of Public Health, \\ University of Michigan, Ann Arbor, MI 48109, U.S.A.
}

(Received 7 August 1984)

\begin{abstract}
In vitro inhibition of rat liver mitochondrial and microsomal aldehyde dehydrogenase $(\mathrm{ALDH})$ under conditions of active $\mathrm{CCl}_{4}$ metabolism was investigated.

2. Incubation of microsomes or mitochondria in the presence of NADPH alone caused significant, time-dependent inhibition of mitochondrial and microsomal ALDH. EDTA partially protected ALDH from inhibition.

3. Incubation of microsomes or microsomes plus mitochondria in the presence of NADPH and $\mathrm{CCl}_{4}$ resulted in marked inhibition of microsomal and mitochondrial ALDH activity. The inhibition was both dose- and time-dependent and was relatively less in the presence of EDTA.

4. It is proposed that the inhibition of membrane-bound ALDH may be one of the early events responsible for the genesis of $\mathrm{CCl}_{4}$-hepatotoxicity.
\end{abstract}

\section{INTRODUCTION}

Aldehydes occur ubiquitously in nature. In the animal body they are produced enzymatically during the metabolism of endogenous or exogenous chemicals. Tissue aldehyde dehydrogenase (ALDH) represents one of the primary determinants of their biological fate and toxicity (Weiner, 1980).

Recent work has documented a possible role of acetaldehyde in the acute and chronic toxicity of ethanol (Burke and Rubin, 1979; Williams et al., 1980; Lieber, 1980; Lieber et al., 1981). Also, disulfiram-induced aversion of voluntary ethanol consumption has been attributed to its known potential to cause the accumulation of acetaldehyde subsequent to ALDH inhibition (Marchner and Tottmar, 1978; Hoover and Brien. 1981; Cederbaum, 1981). Acetaldehyde forms adducts with protein (Benedetti et al., 1982), phospholipids (Kennedy, 1982), and induces lipid peroxidation in the isolated rat hepatocytes (Stege, 1982) as well as in hepatic microsomes (Kornbrust and Mavis, 1980). Lipid peroxidation whether occurring from normal tissue aging or that triggered by xenobiotics, generates a plethora of toxic aldehydes, some of which, including malondialdehyde (MDA), have been shown to be substrates for ALDH (Horton and Packer, 1970; Hakki and Nodes, 1979; Hjelle et al., 1982c).

The role of lipid peroxidation and covalent binding of reactive metabolites in $\mathrm{CCl}_{4}$-caused liver injury has been a subject of continued debate for the past several years (Recknagel, 1983; Smith et al., 1983). With the dismissal of the most recent hypothesis that

*Present address: Staff Toxicologist, International Research and Development Corporation, Mattawan, MI, U.S.A.

$\dagger$ The results reported in this paper are part of the Ph.D. thesis submitted by M. F. Kenel to the University of Michigan. A brief account of this work was published in Toxicologist 2, 39 (1982).
$\mathrm{CCl}_{4}$ disturbs cell caicium homeostasis (Recknagel, 1983), the question regarding the mechanism of $\mathrm{CCl}_{4}$ hepatotoxicity remains unanswered. A number of studies have documented potentiation of $\mathrm{CCl}_{4}$ hepatotoxicity by alcohols (Cornish and Adefuin, 1967; Traiger and Plaa, 1971; Cantillena et al., 1979). An accumulation of acetaldehyde was also shown in the blood of animals receiving $\mathrm{CCl}_{4}$ and a subsequent dose of ethanol (Hjelle and Petersen, 1981; Hjelle et al., 1982a). The inhibition of liver mitochondrial ALDH resulting from $\mathrm{CCl}_{4}$-stimulated lipid peroxidation was implicated to explain these observations (Hjelle and Petersen, 1981; Hjelle et al., 1981, 1983). However, appropriate in vitro experiments were not performed to elucidate the underlying biochemical mechanisms responsible for the ALDH inhibition in intact mitochondria (Hjelle et al., 1981). Besides mitochondria a significant ALDH activity is associated with the liver microsomal fraction (Tottmar et al., 1973; Lindhal, 1981). Since endoplasmic reticulum is the primary locus of $\mathrm{CCl}_{4}$ metabolism and concomitant lipid peroxidation, a high degree of inhibition of microsomal ALDH is expected. In view of the fact that rat liver microsomal and mitochondrial ALDH activity accounts for a major portion $(>80 \%$ ) of the total hepatic ALDH activity (Tottmar et al., 1973; Horton and Barrett, 1975; Sjoblom et al., 1978) we have re-examined the issue of susceptibility of these membrane-bound ALDHs to $\mathrm{CCl}_{4}$ inhibition. The results of in vitro experiments reported in this paper demonstrate that under the conditions of $\mathrm{CCl}_{4}$ metabulism, a significant inhibition of mitochondrial and microsomal ALDH occurs.

\section{MATERIALS AND METHODS}

Reagent grade $\mathrm{CCl}_{4}$ was purchased from the Fisher Scientific Company, Pittsburgh, PA. Amytal, pyrazole, deoxycholic acid, NADP ${ }^{+}, \mathrm{NAD}^{+}$, and NADPH were 
obtained from the Sigma Chemical Company, St Louis, MO. Disodium EDTA, and monobasic and dibasic sodium phosphate were products of Mallinkrodt.

Male $200-250 \mathrm{~g}$ Sprague-Dawley rats were purchased from Charles River, Portage, MI. The rats had free access to water and Purina Laboratory Rodent Chow. Upon sacrifice livers were rapidly removed, weighed, and placed in ice-cold isolation medium (IM) containing $10 \mathrm{mM}$ sodium

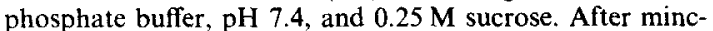
ing and rinsing the tissue sample several times in IM, a $10 \%$ (w/v) homogenate was prepared using a hand glass homogenizer. Mitochondria were obtained by the centrifugation of the postnuclear fraction at $10,000 \mathrm{~g}$ for $20 \mathrm{~min}$. Postmitochondrial supernatant was centrifuged at $104,000 \mathrm{~g}$ for $1 \mathrm{hr}$ to obtain microsomes and cytosol. Both mitochondria and microsomal fractions were washed by resuspension in an equal volume of IM followed by resedimentation.

Microsomes $(2 \mathrm{mg}$ protein $/ \mathrm{ml})$ were incubated with or without mitochondria $(2 \mathrm{mg}$ protein $/ \mathrm{ml})$ in the presence of $\mathrm{CCl}_{4}(0.0-1.0 \mu 1 / \mathrm{mg}$ microsomal protein) and/or NADPH $(1.0 \mathrm{mM})$ at $37^{\circ} \mathrm{C}$. Reactions were stopped by rapid cooling of reaction flasks in an ice-water bath. Each reaction mixture was then centrifuged at $10,000 \mathrm{~g}$ for $20 \mathrm{~min}$ and/or subsequently at $104,000 \mathrm{~g}$ for $1 \mathrm{hr}$ to resediment mitochondria and microsomes, respectively. The supernatant containing NADPH was discarded. Microsomes and mitochondria were then resuspended separately in $50 \mathrm{mM}$ sodium phosphate, $\mathrm{pH} 8.8$, and assayed for remaining ALDH activity. The justification for such an experimental design rests with the known continuity of these membranes and direct juxtaposition often found between microsomes and mitochondria in hepatocytes (Pickett et al., 1980).

Both $\mathrm{NAD}^{+}$- and $\mathrm{NADP}^{+}$-dependent $\mathrm{ALDH}$ in rat microsomes and mitochondria were assayed for total ALDH activity (isozymes I + II) using a modification of the procedure described by Tottmar et al. (1973). The assay mixture contained $1 \mathrm{mg} / \mathrm{ml}$ protein, $0.5 \mathrm{mM} \mathrm{NAD}{ }^{+}$or $2.5 \mathrm{mM}$ NADP ${ }^{+}, 0.25 \mathrm{mg}$ deoxycholate $/ \mathrm{mg}$ protein, $2 \mathrm{mM}$ amytal, and $50 \mathrm{mM}$ sodium phosphate buffer, $\mathrm{pH} 8.8$. After $3 \mathrm{~min}$ of preincubation the reactions were started with $5 \mathrm{mM}$ acetaldehyde and $\mathrm{NAD}(\mathrm{P}) \mathrm{H}$ production was monitored at
$340 \mathrm{~nm}$ in an Aminco DW2 spectrophotometer at $37^{\circ} \mathrm{C}$. Protein content was determined by the Biuret method (Gornall et al., 1949).

Statistical analysis consisted of analysis for variance followed by Dunnett's $t$-test for comparison of test groups with controls. Significance was assumed at $P \leq 0.05$.

\section{RESULTS}

It has been repeatedly documented (see Recknagel, 1983; Smith et al., 1983) that $\mathrm{CCl}_{4}$ is metabolized when rat hepatic microsomes are incubated in the presence of NADPH. This reaction is also accompanied by covalent binding of reactive metabolites of $\mathrm{CCl}_{4}$ and extensive peroxidation of membrane lipids.

The effects of preincubation of microsomes or microsomes plus mitochondria in the presence of NADPH alone or NADPH and $\mathrm{CCl}_{4}$ on ALDH activity are shown in Fig. 1. A significant timedependent decline in both $\mathrm{NAD}^{+}$- and $\mathrm{NADP}^{+}$ coupled mitochondrial and microsomal ALDH activity was observed in the presence of NADPH alone. NAD $(P)^{+}$-dependent microsomal ALDH was found to be more susceptible than mitochondrial activity. As compared to NADPH alone, the preincubation with $\mathrm{NADPH}$ and $\mathrm{CCl}_{4}(1 \mu \mathrm{l} / \mathrm{mg}$ protein) resulted in an even greater decrease in the ALDH activity of both the membranes. This decline was time dependent and after $20 \mathrm{~min}$ of incubation caused up to $96 \%$ inhibition of ALDH. In contrast to the results obtained with NADPH alone, incubation with NADPH plus $\mathrm{CCl}_{4}$ not only resulted in much higher ALDH inhibition but both mitochondrial as well as microsomal ALDH appeared to be nearly equally susceptible.

The data given in Fig. 2(A) indicate that this time-dependent inhibition of microsomal ALDH in-

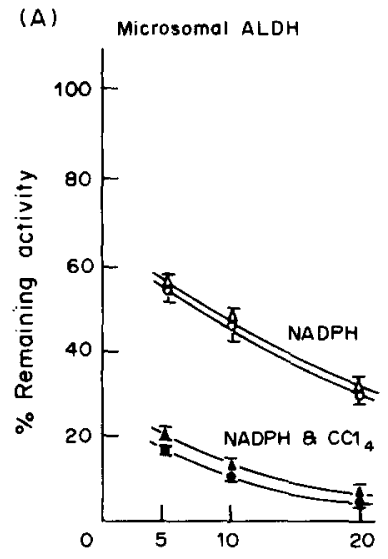

(8)

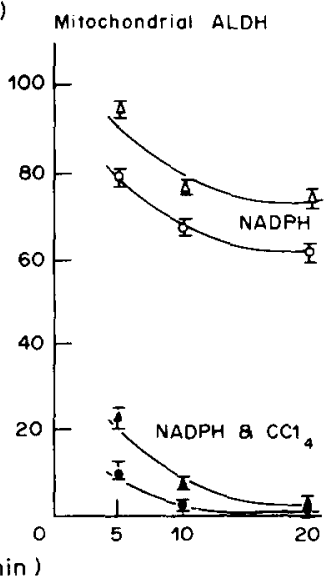

Fig. 1. In vitro inhibition of mitochondrial and microsomal ALDH during $\mathrm{CCl}_{4}$ metabolism: time dependence. Rat hepatic microsomes $(2.0 \mathrm{mg}$ protein $/ \mathrm{ml})(\mathrm{A})$, or microsomes $(2.0 \mathrm{mg}$ protein $/ \mathrm{ml})$ plus mitochondria $(2.0 \mathrm{mg}$ protein $/ \mathrm{ml})(\mathrm{B})$ were preincubated $\left(5 \mathrm{ml}\right.$ final vol) at $37^{\circ} \mathrm{C}$ for 5,10 , and $20 \mathrm{~min}$ in the presence of $1.0 \mathrm{mM}$ NADPH or $1.0 \mathrm{mM} \mathrm{NADPH}$ and $1 \mu 1 \mathrm{CCl}_{4} / \mathrm{mg}$ protein. ALDH activity of mitochondria and microsomes remaining after incubation was assayed with $\mathrm{NAD}^{+}(0.5 \mathrm{mM})$ (triangles) or $\mathrm{NADP}^{+}(2.5 \mathrm{mM})$ (circles) as described under Materials and Methods. Control values (at $0 \mathrm{~min}$ ) for $\mathrm{NAD}^{+}$- and $\mathrm{NADP}^{+}$-coupled microsomal $\mathrm{ALDH}$ were $35.0 \pm 1.9$ and $14.2 \pm 0.5 \mathrm{nmol} / \mathrm{min}$ per mg protein, respectively. Control values (at $0 \mathrm{~min}$ ) for $\mathrm{NAD}^{+}$- and $\mathrm{NADP}^{+}$-coupled mitochondrial ALDH were $45.4 \pm 2.1$ and $10.2 \pm 0.2 \mathrm{nmol} / \mathrm{min}$ per $\mathrm{mg}$ protein, respectively. Control values did not significantly change during 20 -min incubation period. Each value represents the mean $\pm S$.E. for four separate experiments. 
(A)

Mierosomal ALDH
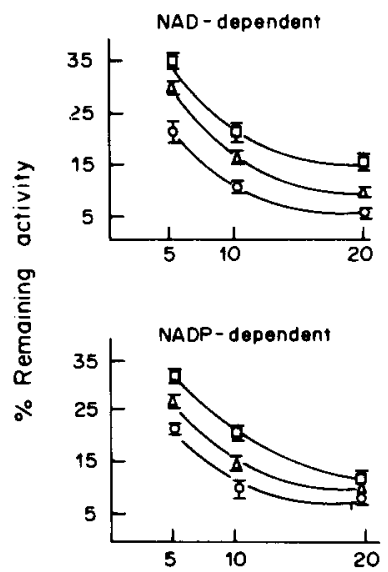

(B)

Mitochondrial ALDH
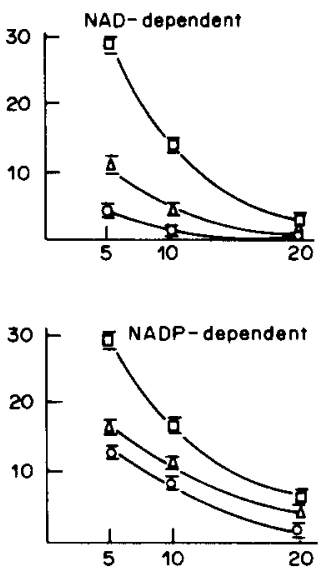

Time ( $\mathrm{min}$ )

Fig. 2. In vitro inhibition of microsomal and mitochondrial ALDH during $\mathrm{CCl}_{4}$ metabolism: dose dependence. Rat hepatic microsomes $(2.0 \mathrm{mg}$ protein $/ \mathrm{ml})(\mathrm{A})$ or microsomes $(2.0 \mathrm{mg}$ protein $/ \mathrm{ml})$ plus mitochondria $(2.0 \mathrm{mg}$ protein $/ \mathrm{ml})(\mathrm{B})$ were incubated $\left(5 \mathrm{ml}\right.$ final vol) at $37^{\circ} \mathrm{C}$ for 5,10 , and $20 \mathrm{~min}$ in the presence of $1.0 \mathrm{mM} \mathrm{NADPH}$ and 0.25 (squares) 0.5 (triangles), or 1.0 (circles) $\mu \mathrm{l}$ of $\mathrm{CCl}_{4} / \mathrm{mg}$ protein. ALDH activity of mitochondria and microsomes remaining after incubation was estimated as described under Materials and Methods. Control values (at $0 \mathrm{~min}$ ) for $\mathrm{NAD}^{+}$- and $\mathrm{NADP}^{+}$-coupled microsomal ALDH were $44.5 \pm 3.0$ and $7.5 \pm 1.6 \mathrm{nmol} / \mathrm{min}$ per $\mathrm{mg}$ protein, respectively. Control values (at $0 \mathrm{~min}$ ) for $\mathrm{NAD}^{+}$- and NADP ${ }^{+}$-dependent mitochondrial ALDH were $42.0 \pm 1.5$ and $12.3 \pm 0.9 \mathrm{nmol} / \mathrm{min}$ per $\mathrm{mg}$ protein, respectively. Control values did not significantly change during $20 \mathrm{~min}$ incubation period. Each point represents the mean \pm S.E. for four separate experiments.

hibition is also a dose related phenomenon. Although a significant decrease in microsomal ALDH activity can be seen in $5 \mathrm{~min}$, the data given in Fig. 2(B) suggest that mitochondrial ALDH is even more susceptible. These results also indicate that, in general, the degree of inhibition is independent of the kind of oxidized pyridine nucleotide used for assaying either microsomal or mitochondrial ALDH.
The effects of EDTA on the inhibition of the mitochondrial and microsomal ALDH activity are given in Fig. 3. The amount of activity remaining After 20-min incubations with NADPH alone was about 30 and $60 \%$ for $\mathrm{NAD}^{+}$-dependent microsomal and mitochondrial ALDH, respectively. The addition of EDTA $(0.2 \mathrm{mM})$ resulted in relatively less inhibition. After incubation in the presence of NADPH
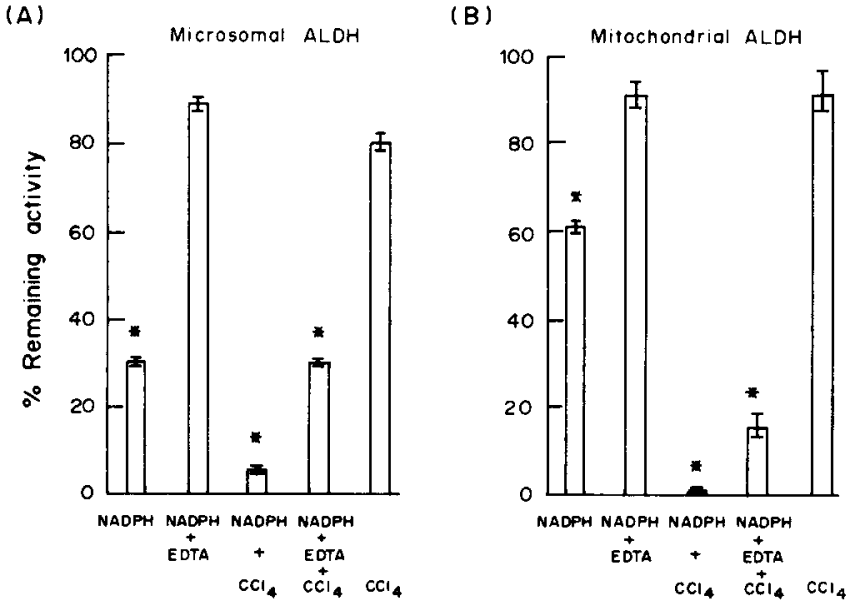

Fig. 3. Effects of EDTA on in vitro inhibition of microsomal and mitochondrial ALDH during $\mathrm{CCl}_{4}$ metabolism. Rat hepatic microsomes $(2.0 \mathrm{mg}$ protein $/ \mathrm{ml})$ or microsomes $(2.0 \mathrm{mg}$ protein $/ \mathrm{ml})$ plus mitochondria $(2.0 \mathrm{mg}$ protein $/ \mathrm{ml})$ were incubated $\left(5 \mathrm{ml}\right.$ final vol) at $37^{\circ} \mathrm{C}$ for $20 \mathrm{~min}$ with $1.0 \mathrm{mM}$ $\mathrm{NADPH}$, and/or $1.0 \mu \mathrm{l} \mathrm{CCl}_{4} / \mathrm{mg}$ and/or $0.2 \mathrm{mM}$ EDTA as indicated. ALDH activity of mitochondria and microsomes remaining after 20 -min incubation was estimated as described under Materials and Methods. Control values (at $0 \mathrm{~min}$ ) for $\mathrm{NAD}^{+}$-dependent microsomal and mitochondrial ALDH were $35.0 \pm 1.9$ and $41.9 \pm 0.7 \mathrm{nmol} / \mathrm{min}$ per $\mathrm{mg}$ protein, respectively, in the presence of EDTA. Each value represents the mean \pm S.E. for four separate experiments. ${ }^{*}$ Statistically significant $(p \leq 0.05)$ from control value. 


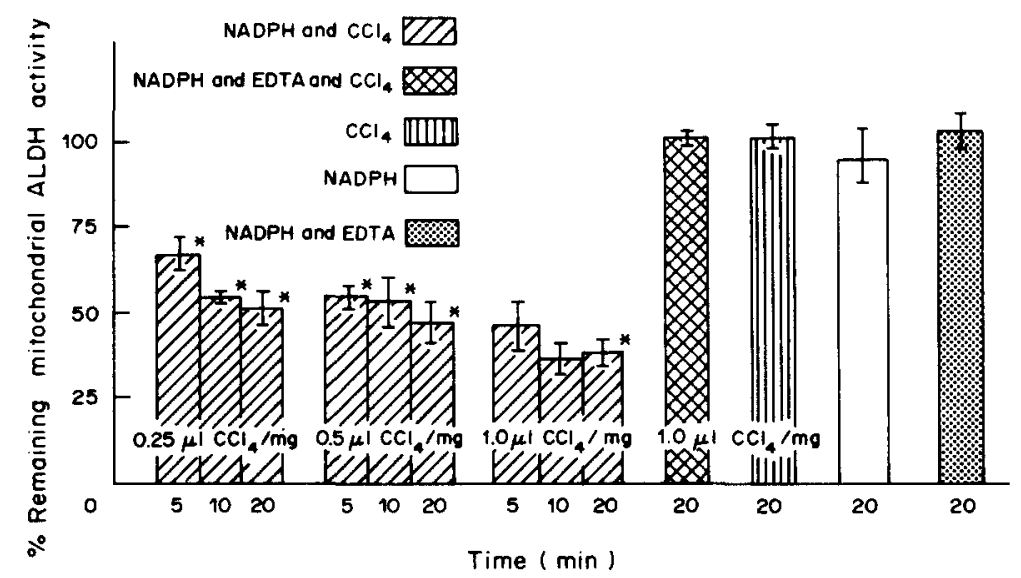

Fig. 4. Effect of $\mathrm{CCl}_{4}$ on the mitochondrial ALDH activity. Washed rat liver mitochondrial (2 $\mathrm{mg}$ protein $/ \mathrm{ml}$ ) were incubated $(5 \mathrm{ml}$ final vol $)$ at $37^{\circ} \mathrm{C}$ for 5,10 , or $20 \mathrm{~min}$ in the presence of $1.0 \mathrm{mM} \mathrm{NADPH}$, $0.25,0.5$, or $1.0 \mu 1 \mathrm{CCl}_{4} / \mathrm{mg}$, and $0.2 \mathrm{mM}$ EDTA as indicated. ALDH activity of mitochondria remaining after 20-min incubation was determined as indicated. See text for further details. Control value (after $20 \mathrm{~min}$ ) for $\mathrm{NAD}^{+}$-dependent ALDH was $39.7 \pm 2.7 \mathrm{nmol} / \mathrm{min}$ per $\mathrm{mg}$ protein. Each value represents the mean \pm S.E. for four separate experiments. *Statistically significant $(p \leq 0.05)$ from control value.

and $\mathrm{CCl}_{4}$ for 20 min only 5 and $0.5 \%$ of $\mathrm{NAD}^{+}$dependent microsomal and mitochondrial ALDH activity remained, respectively. Under these conditions the inclusion of EDTA resulted in only a partial restoration of microsomal (to $30 \%$ of control values) and mitochondrial (to $15 \%$ of control values) ALDH activity. Furthermore, the inability of unmetabolized $\mathrm{CCl}_{4}$ to significantly inhibit ALDH activity clearly attests that the observed inhibition was not due to solvent effects of $\mathrm{CCl}_{4}$.

Besides microsomes, $\mathrm{CCl}_{4}$ was shown to be metabolized by rat liver mitochondria (Castro et al., 1984). To assess the role of mitochondrial activation in ALDH inhibition, $\mathrm{CCl}_{4}$ was preincubated in the presence of NADPH and washed mitochondria. Apparently the isolation procedure employed renders mitochondria permeable to NADPH and retains their capacity to metabolize $\mathrm{CCl}_{4}$. However, some unavoidable microsomal contamination is likely to be present in the mitochondrial preparations used. The data given in Fig. 4 indicate a substantial time- and dose-dependent inhibition of $\mathrm{NAD}^{+}$-coupled ALDH when mitochondria were incubated with NADPH plus $\mathrm{CCl}_{4}$. The decline in specific activity of mitochondrial ALDH was significantly greater with NADPH plus $\mathrm{CCl}_{4}$ than with NADPH alone and this inhibition vas not observed in the presence of EDTA.

\section{DISCUSSION}

Bioactivation catalyzed by the microsomal cytochrome P-450 system is a prerequisite well accepted in $\mathrm{CCl}_{4}$ hepatotoxicity. Despite numerous investigations, the specific biochemical event(s) responsible for hepatocyte dysfunction leading to fatty infiltration and cell death after $\mathrm{CCl}_{4}$ poisoning is largely unknown. The role of covalent binding of reactive metabolites, lipoperoxidation as well as depression of calcium pump activity have been a subject of continuing debate (Recknagel, 1983; Smith et al., 1983).

Our results confirm the reports (Tottmar et al., 1973; Lindahl, 1981) that significant rat hepatic
ALDH activity exists in the microsomal and mitochondrial fractions. When microsomes or microsomes plus mitochondria were incubated in the presence of NADPH alone, a significant time-dependent decline in hepatic $\mathrm{NAD}^{+}-$and $\mathrm{NADP}^{+}$-coupled mitochondrial and microsomal ALDH was observed (Fig. 1). These results suggest a possible involvement of lipid peroxidation in ALDH inhibitions since similar treatment has been shown to trigger lipoperoxidation in liver microsomal preparations (Levin et al., 1973; Kulkarni and Hodgson, 1981) and it is believed to be due to the presence of metal contaminants in the reagents used. Furthermore, a recent study (Hjelle et al., 1982b) has demonstrated MDA, a major product of lipid peroxidation, to inhibit mitochondrial ALDH.

In vitro metabolism of $\mathrm{CCl}_{4}$ leading to concomitant lipid peroxidation and covalent binding of reactive metabolites is well documented (Recknagel, 1983). Preincubation with $\mathrm{NADPH}+\mathrm{CCl}_{4}$ significantly increased the loss of ALDH activity in both microsomes and mitochondria, when compared to NADPH alone. This was a dose-related phenomenon. The decline was also time dependent and after 5 min of incubation, microsomal and mitochondrial ALDH was inhibited $c a .80 \%$. It has been shown that within $5 \mathrm{~min}$ after administration, $\mathrm{CCl}_{4}$ is detected in liver microsomes and that within $15 \mathrm{~min} \mathrm{CCl}_{4}$-stimulated lipid peroxidation as well as covalent binding of ${ }^{14} \mathrm{C}$ and ${ }^{14} \mathrm{CCl}_{4}$ to macromolecules is maximal (Rao and Recknagel, 1968, 1969). Therefore, our data suggest that $\mathrm{CCl}_{4}$-dependent inhibition of membrane bound ALDH may occur prior to an overt hepatotoxic response.

The facts that postnuclear supernatant of rat liver when similarly incubated in the presence of NADPH and $\mathrm{CCl}_{4}$ does not result in a significant inhibition of mitochondrial ALDH (data not shown) and EDTA protects mitochondria from inhibition (Fig. 4) tend to suggest a predominant role of lipoperoxidation in the observed ALDH inactivation. This view is consistent with reports on inhibition of microsomal lipid per- 
oxidation by the cytosolic constituents (Kamataki et al., 1974; Kulkarni and Hodgson, 1981).

To further test this hypothesis, incubations were performed in the presence of $0.2 \mathrm{mM}$ EDTA (Fig. 3), a concentration shown to block metal-, but not $\mathrm{CCl}_{4^{-}}$, stimulated lipid peroxidation (Kornbrust and Mavis, 1980; Waller and Recknagel, 1982). The protective effect noted suggests that the observed inhibition of ALDH, due to NADPH alone, could be attributed to metal-dependent, NADPH-stimulated lipid peroxidation. The EDTA-dependent partial restoration of microsomal and mitochondrial ALDH suggests that the binding of free radicals or products of $\mathrm{CCl}_{4}$ stimulated lipid peroxidation may be responsible for the observed inhibition of ALDH. Similar protective effects were also observed by Hjelle et al. (181) in the presence of glutathione. The inability of $\mathrm{CCl}_{4}$ alone to significantly inhibit microsomal or mitochondrial ALDH (Fig. 3) eliminates the role of solvent effects and suggests that bioactivation of $\mathrm{CCl}_{4}$ is a prerequisite for $A L D H$ inactivation.

A significant decrease in $\mathrm{NAD}^{+}$-dependent ALDH activity observed in the presence of $\mathrm{NADPH}+\mathrm{CCl}_{4}$ as compared to NADPH alone (Fig. 4) suggests that mitochondria may be capable of $\mathrm{CCl}_{4}$ bioactivation. However, it should be kept in mind that contaminating microsomes may be partially contributing to the activation process. In any case, the magnitude of inhibition of mitochondrial ALDH observed in these experiments (Fig. 4) is much smaller than that observed in incubations in the presence of both mitochondria and microsomes (Fig. 3b). This is rather expected from the relatively lower efficiency of mitochondria to metabolize $\mathrm{CCl}_{4}$ than microsomes.

Hjelle et al. (1981) incubated isolated mitochondrial ALDH preparation containing $1 \mathrm{mM}$ dithiothreitol in the presence of microsomes, NADPH and $\mathrm{CCl}_{4}$ and the incubates were sampled periodically and directly assayed for ALDH activity. The authors reported essentially complete inhibition of mitochondrial ALDH within $5 \mathrm{~min}$. The reliability of their data is somewhat questionable since the mitochondrial ALDH was apparently measured in the presence of microsomes and other components of the incubation mixture. The inhibition of microsomal ALDH (Figs 1-3), the stimulation of lipid peroxidation by dithiothreitol (Kulkarni and Hodgson, 1981), the measurement of ALDH in the presence of NADPH, a regulatory inhibitor of ALDH (Kenel and Kulkarni, unpublished observations) will each introduce an error in the estimation of mitochondrial ALDH activity. It is known that lipophilic aldehydic products of lipid peroxidation are preferentially contained in the membranes and only a small fraction escapes into the surrounding (Esterbauer et al., 1982). In view of this, the reported inhibition of mitochondrial ALDH (Hjelle et al., 1981) may have been partly due to diffusable products of lipid peroxidation. Our data based on re-sedimented mitochondria and microsomes suggest that membrane-bound products of lipid peroxidation also possess high inhibitory potency.

Ability of $\mathrm{CCl}_{4}$ to decrease the specific activities of these membrane-bound ALDH may severely compromise the cells' capacity to metabolize acetaldehyde or aldehydic products of lipid peroxidation.
Because of their high toxicity, reactivity, and in some cases high stability (Benedetti et al., 1982, 1984; Esterbauer et al., 1982) these aldehydes are capable of binding to tissue macromolecules causing enzyme inactivation or capable of being transported to distant loci to produce toxicity at sites other than their origin. Although the precise events leading to cellular pathology remain unknown, it has been suggested (Lowrey et al., 1981) that the underlying biochemical mechanism may involve inhibition of several vital enzyme systems. Our data suggest that ALDH inhibition may represent one of the important enzyme systems that is significantly affected during early stages of $\mathrm{CCl}_{4}$ poisoning. The results of the in vivo experiments (reported elsewhere) confirm this view.

Acknowledgement-This work was supported in part by the grant T32 ES0062 from the U.S. Public Health Service, National Institute of Environmental Health Sciences.

\section{REFERENCES}

Benedetti A., Comporti M., Fulceri R. and Esterbauer H (1984) Cytotoxic aldehydes originating from the peroxidation of liver microsomal lipids: identification of 4,5-dihydroxydecenal. Biochim. biophys. Acta 792, 172-181.

Benedetti A., Esterbauer H., Ferrali M., Fulceri R. and Comporti M. (1982) Evidence for aldehydes bound to liver microsomal protein following $\mathrm{CCl}_{4}$ or $\mathrm{BrCCl}_{3}$ poisoning. Biochim biophys. Acta 11, 345-356.

Burke J. P. and Rubin E. (1979) The effects of ethanol and acetaldehyde on the products of protein synthesis by liver mitochondria. Lab. Invest. 41, 393-400.

Cantillena L. R., Cagen S. Z. and Klaassen C. D. (1979) Methanol potentiation of carbon tetrachloride induced hepatotoxicity. Proc. Soc. exp. Biol. Med. 162, 29-95.

Castro C. E., Fernandex G., Villarruel M. C., Barnacchi A. and Castro J. A. (1984) Carbon tetrachloride activation in rat liver mitochondria. Toxic. Lett. 18 (Suppl.), 42.

Cederbaum A. I. (1981) The effect of cyanamide on acetaldehyde oxidation by isolated rat liver mitochondria and on the inhibition of pyruvate oxidation by acetaldehyde. Alcoholism: Clin. exp. Res. 5, 38-44.

Cornish H. H. and Adefuin J. (1967) Potentiation of carbon tetrachloride toxicity by aliphatic alcohols. Archs environ Hith 14, 447-449.

Esterbauer H., Cheeseman K. H., Dianzani M. V., Poli G. and Slater R. F. (1982) Separation and characterization of the aldehydic products of lipid peroxidation stimulated by $\mathrm{ADP}-\mathrm{Fe}^{2+}$ in rat liver microsomes. Biochem. $J .208$, $129-140$.

Gornall A. G., Bardawill C. J. and David M. M. (1949) Determination of serum proteins by means of the biuret reaction. J. biol. Chem. 177, 751-760.

Hakki S. F. I. and Nodes J. T. (1979) Metabolism of Hhydroxy-2,3-pentene-1-al in submitochondrial fractions of mouse liver. Chem.-Biol. Inter. 25, 363-368.

Hjelle J. J., Gordon A. S. and Petersen D. R. (1982a) Studies on carbon tetrachloride-ethanol interactions in mice. Toxic. Lett. 10, 17-24.

Hjelle J. J., Grubbs J. H., Beer D. G. and Petersen D. R. (1981) Inhibition of rat liver aldehyde dehydrogenase by carbon tetrachloride. J. Pharmac. exp. Ther. 219, $821-826$.

Hjelle J. J., Grubbs J. H., Beer D. G. and Petersen D. R. (1983) Time course of the carbon tetrachloride-induced decrease in mitochondrial aldehyde dehydrogenase activity. Toxic. appl. Pharmac. 67, 159-165.

Hjelle J. J., Grubbs J. H. and Petersen D. R. (1982b) Inhibition of mitochondrial aldehyde dehydrogenase by malondialdehyde. Toxic. Lett. 14, 35-43. 
Hjelle J. J., Grubbs J. H. and Petersen D. R. (1982c) Metabolism of malondialdehyde by rat liver aldehyde dehydrogenase. Toxicologist 2, 24.

Hjelle J. J. and Petersen D. R. (1981) Decreased in vivo acetyldehyde oxidation and hepatic aldehyde dehydrogenase inhibition in $\mathrm{C}_{57} \mathrm{BL}$ and DBA mice treated with carbon tetrachloride. Toxic. appl. Pharmac. 59, 15-24.

Hoover D. J. and Brien J. F. (1981) Acetaldehyde concentration in rat blood and brain during the calcium carbimide-ethanol interaction. Can. J. Physiol. Pharmac. 59, $65-70$.

Horton A. A. and Barrett M. C. (1975) The subcellular localization of aldehyde dehydrogenase in rat liver. Archs Biochem. Biophys. 167, 426-436.

Horton A. A. and Packer L. (1970) Interactions between malondialdehyde and rat liver mitochondria. J. Geront. 25, 199-204.

Kamataki T., Ozawa N, Kitada $\mathbf{M}$. and Kitagawa $\mathbf{H}$. (1974) The occurrence of an inhibitor of lipid peroxidation in rat liver soluble fraction and its effect on microsomal drug oxidations. Biochem. Pharmac. 17, 404-414.

Kennedy A. (1982) Acetyldehyde adducts of phospholipids. Alcoholism 6, 412.

Kornbrust D. J. and Mavis R. D. (1980) Microsomal lipid peroxidation. II. Stimulation by carbon tetrachloride. Molec. Pharmac. 17, 404-414.

Kulkarni A. P. and Hodgson E. (1981) A comparison of NADPH and cumene hydroperoxidase-stimulated lipid peroxidation in mouse hepatic microsomes. Int. J. Biochem. 13, 811-816.

Levin W. L., Lu A. Y. A., Jacobson M., Kuntzman R., Poyer J. L. and McCay P. B. (1973) Lipid peroxidation and the degradation of cytochrome P-450. Archs Biochem. Biophys. 158, 842-852.

Lieber C. S. (1980) Metabolism and metabolic effects of alcohol. Sem. Hemat. 17, 85-99.

Lieber C. S., Baraona E., Matsuda Y., Salaspuro M., Hasumura Y. and Matsuzaki S. (1981) Hepatotoxicity of acetaldehyde. Adv. exp. Med. Biol. 126, 397-411.

Lindahl R. (1981) Subcellular distribution and properties of rabbit liver aldehyde dehydrogenases. Biochem. Pharmac. 30, $441-446$.

Lowrey K., Glende E. A. and Recknagel R. O. (1981) Rapid depression of rat liver microsomal calcium pump activity after administration of carbon tetrachloride or bromo- trichloromethane and lack of effect after ethanol. Toxic. appl. Pharmac. 59, 389-394.

Marchner H. and Tottmar O. (1978) A comparative study on the effects of disulfiram, cyanamide, and 1 -aminocyclopropanol on acetaldehyde metabolism in rats. Acta Pharmac. Toxic. 43, 219-232.

Pickett C. B., Montisano D., Eianer D. and Cascarano J. (1980) The physical association between rat liver mitochondria and rough endoplasmic reticulum. Expl Cell. Res. 128, 343-352.

Rao K. S. and Recknagel R. O. (1968) Early onset of lipoperoxidation in rat liver after carbon tetrachloride administration. Exp. molec. Path. 9, 271-278.

Rao K. S. and Recknagel R. O. (1969) Early incorporation of carbon-labelled carbon tetrachloride into rat liver particulate lipids and proteins. Exp. molec. Path. 10, 219-228.

Recknagel R. O. (1983) A new direction in the study of carbon tetrachloride hepatotoxicity. Life Sci. 33, 401-408.

Sjoblom M., Pilstrom L. and Morland J. (1978) Activity of alcohol dehydrogenase and acetaldehyde dehydrogenases in the liver and placenta during the development of the rat. Enzyme 23, 108-115.

Smith M. T., Thor H. and Orrenius S. (1983) The role of lipid peroxidation in the toxicity of foreign compounds to liver cells. Biochem. Pharmac. 32, 763-764.

Stege T. E. (1982) Acetaldehyde induced lipid peroxidation in isolated hepatocytes. Res. Commun. chem. Path. Pharmac. 36, 287-297.

Tottmar S. O. C., Petersson H. and Kiessling K. H. (1973) The subcellular distribution and properties of aldehyde dehydrogenases in rat liver. Biochem. J. 135, 577-586.

Traiger C. J. and Plaa G. L. (1971) Differences in the potentiation of carbon tetrachloride in rats by ethanol and isopropanol pretreatment. Toxic. appl. Pharmac. 20, 105-112.

Waller R. L. and Recknagel P. O. (1982) Evaluation of a role for phosgene production in the hepatotoxic mechanism of action of carbon tetrachloride and bromotrichloromethane. Toxic. appl. Pharmac. 66, 172-181.

Weiner W. (1980) Aldehyde oxidizing enzymes. In Enzymatic Basis of Detoxication (Edited by Jakoby W. B.), Vol. 1, pp. 261-280. Academic Press, New York.

Williams E. S., Mirro M. J. and Bailey J. C. (1980) Electrophysiological effects of ethanol, acetaldehyde, and acetic acid on cardiac tissues from dog and guinea pig. Circulation Res. 47, 473-478. 